\title{
Comments and Reply to: Foot Plantar Pressure Measurement System: A Review. Sensors 2012, 12, $9884-9912$
}

Nachiappan Chockalingam ${ }^{1, *}$, Aoife Healy ${ }^{1}$, Roozbeh Naemi ${ }^{1}$, Philip Burgess-Walker ${ }^{1}$, Abdul Hadi Abdul Razak ${ }^{2,3, *}$, Aladin Zayegh ${ }^{2}$, Rezaul K. Begg ${ }^{4}$ and Yufridin Wahab ${ }^{5}$

1 Centre for Sport, Health and Exercise Research, Faculty of Health Sciences, Staffordshire University, ST4 2DF, UK; E-Mails: a.healy@staffs.ac.uk (A.H.); r.naemi@staffs.ac.uk (R.N.); p.burgess-walker@staffs.ac.uk (P.B.-W.)

2 School of Engineering and Science, Victoria University, Melbourne 3000, Australia; E-Mail: Aladin.Zayegh@vu.edu.au

3 Faculty of Electrical Engineering, Universiti Teknologi MARA, Shah Alam 40000, Selangor, Malaysia

4 Institute of Sport, Exercise and Active Living (ISEAL) and School of Sport and Exercise Science (SES), Victoria University, Melbourne 3000, Australia; E-Mail: Rezaul.Begg@vu.edu.au

5 Centre for Industrial Collaboration, School of Microelectronic Engineering, Universiti Malaysia Arau, Perlis 02600, Malaysia; E-Mail: yufridin@unimap.edu.my

* Authors to whom correspondence should be addressed;

E-Mails: n.chockalingam@staffs.ac.uk (N.C.); hadi@ieee.org (A.H.A.R.); Tel.: +44-1782-295-853 (N.C.); Tel.: +61-3-9919-5047 (A.H.A.R.); Fax: +61-3-9919-4908 (A.H.A.R.).

Received: 22 January 2013; in revised form: 18 February 2013 / Accepted: 5 March 2013 / Published: 13 March 2013

\section{Comments}

We would like to comment on a recent review article published in Sensors by Razak et al. [1]. The authors provided a review of plantar pressure measurement systems which included the discussion of the recently developed WalkinSense ${ }^{\circledR}$ system. While the authors correctly identified that our group completed research using this system [2], they have inaccurately reported the manufacturer of the system and our research findings.

The authors stated that this system was developed by our group, however, as stated in our article [2], this system was developed by Tomorrow Options Microelectronics (Sheffield, UK). 
Additionally they stated inaccurately that the WalkinSense ${ }^{\circledR}$ system is similar to the F-Scan ${ }^{\circledR}$ (Tekscan, Boston, MA, USA) hardware and software and that our research concluded that WalkinSense ${ }^{\circledR}$ had a better repeatability when compared to other commercially available systems. Our research [2] clearly concluded that the WalkinSense ${ }^{\circledR}$ system was found to be as repeatable as the F-Scan ${ }^{\circledR}$ system.

There are several papers which outline the existing technologies [3], the protocols used for data collection [4,5] and the repeatability of existing systems [6]. Whilst this paper [1], is mainly intended for a different audience when compared to clinical papers, it is very important that previously published information is carefully considered, critically reviewed and succinctly presented in a review paper.

We felt compelled to write this note so that: (1) it is not misinterpreted that we developed this system and (2) our research findings are not inaccurately reported.

\section{References}

1. Razak, A.; Zayegh, A.; Begg, R.K.; Wahab, Y. Foot Plantar Pressure Measurement System: A Review. Sensors 2012, 12, 9884-9912.

2. Healy, A.; Burgess-Walker, P.; Naemi, R.; Chockalingam, N. Repeatability of WalkinSense ${ }^{\circledR}$ in Shoe Pressure Measurement System: A Preliminary study. The Foot 2012, 22, 35-39.

3. Rosenbaum, D.; Becker, H.P. Review Article: Plantar Pressure Distribution Measurements. Technical Background and Clinical Applications. Foot Ankle Surg. 1997, 3, 1-14.

4. Bus, S.A; de Lange, A. A Comparison of the 1-Step, 2-Step, and 3-Step Protocols for Obtaining Barefoot Plantar Pressure Data in the Diabetic Neuropathic Foot. Clin. Biomech. 2005, 20, 892-899.

5. McPoil, T.G.; Cornwall, M.W.; Dupuis, L.; Cornwell, M. Variability of Plantar Pressure Data. A Comparison of the Two-Step and Midgait Methods. J. Am. Podiatr. Med. Assoc. 1999, 89, 495-501.

6. Ramanathan, A.K.; Kiran, P.; Arnold, G.P.; Wang, W.; Abboud R.J. Repeatability of the Pedar-X ${ }^{\circledR}$ in-shoe pressure measuring system. Foot Ankle Surg. 2010, 16, 70-73.

Nachiappan Chockalingam

Aoife Healy

Roozbeh Naemi

Philip Burgess-Walker

\section{Reply}

We acknowledge your concerns and would like to apologize for the unintended errors in our paper [1] while quoting two points from Healy et al. [2]. Firstly, the manufacturer of the system is inaccurately identified. Secondly, our sentence "has a better repeatability compared to other commercially available systems" should rather read "equal repeatability compared to F-Scan system".

The corrections made are as listed below: 
- On page 9896, lines 12-13, the sentence "has a better repeatability compared to other commercially available systems" should be "equal repeatability compared to the F-Scan ${ }^{\circledR}$ system".

- On page 9897, lines 2-3, the sentence "It appears that only the sensor is their own development, the rest of the system is similar to F-Scan ${ }^{\circledR}$ (Tekscan, USA) hardware and software." should be "The "WalkinSense" system was developed by Tomorrow Options Microelectronics (Sheffield, UK). This portable system's hardware includes eight individual sensors as well as a data acquisition and processing unit, whereas the proprietary software (WalkinSense version 0.96) records and displays plantar pressure profiles".

- On page 9897, line 14, the sentence "developed their own transducer but seems to have a limited number of sensor placements" should be "has a limited number of sensor placements".

- On page 9900, line 24, the sentence "used F-Scan ${ }^{\circledR}$ (Tekscan, USA) for the sensor" should be "used a low-cost pressure transducer".

\section{References}

1. Abdul Razak, A.H.; Zayegh, A.; Begg, R.K.; Wahab, Y. Foot Plantar Pressure Measurement System: A Review. Sensors 2012, 12, 9884-9912.

2. Healy, A.; Burgess-Walker, P.; Naemi, R.; Chockalingam, N. Repeatability of WalkinSense ${ }^{\circledR}$ in Shoe Pressure Measurement System: A Preliminary Study. The Foot 2012, 22, 35-39.

Abdul Hadi Abdul Razak Aladin Zayegh Rezaul K. Begg Yufridin Wahab

(C) 2013 by the authors; licensee MDPI, Basel, Switzerland. This article is an open access article distributed under the terms and conditions of the Creative Commons Attribution license (http://creativecommons.org/licenses/by/3.0/). 